\title{
Enhancing Tourism Industry through Community Participation: A Strategy for Poverty Reduction in Zanzibar, Tanzania
}

\author{
Wakuru Magigi, Haji Ramadhani \\ Moshi University College of Cooperative and Business Studies (A Constituent College of Sokoine University of Agriculture), Moshi, \\ Tanzania. \\ Email: magigi2000@yahoo.com
}

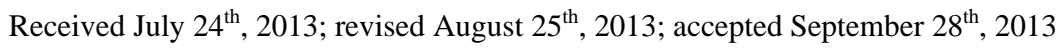

Copyright (C 2013 Wakuru Magigi, Haji Ramadhani. This is an open access article distributed under the Creative Commons Attribution License, which permits unrestricted use, distribution, and reproduction in any medium, provided the original work is properly cited.

\begin{abstract}
This study centred on understanding how local communities participate in tourism industry in Bwejuu Village in Zanzibar and the benefit they are getting towards poverty reduction. Specifically, the study identifies tourism industry activities and how local communities participate in improving their livelihoods, find out factors influencing local community participation in tourism sector and lastly, and identify contribution of tourism sector in enhancing local communities' livelihoods. Interviews, observations, documentary reviews and photograph taking are methods employed to the case. The study result shows that tourist hotels, beach, seaweed, historical building archives, diving and snorkeling, sailing boats, coral reefs and lagoons as well as mangrove swamps are some tourist activities in the settlement. Both men and women involves in the tourist activities. The tourist activities noted contributing to local communities' livelihoods in terms of employment creation, leisure, income generation, increased government revenues, schooling, health, house construction and household consumption. However, language barriers, inadequate experience of operators, poor education and training, culture, commitment of actors and poverty level are some constraints highlighted. Following these challenges, the study recommends that the government in collaboration with other development partners interested in tourism industry development may opt to ensure capacity building to local communities and tourist operators in Zanzibar, to review the policy and legislations in place as well as to encourage stakeholder involvement in Tourism sectors as prospects for its development. In conclusion, it can be asserted that if tourism developers believe that local communities will be satisfied if they are used as labourers instead of being ownership of tourism activities. Thus, there is an urgent need to enhance participation and involvement of local communities in tourism sector. These communities must be actively involved in each stage of tourism planning and development in order to ensure that all their tourism activities and products benefit the residents. This will represent a significant step towards ensuring more adequate community participates in the industry, which is essential sector for sustainable local communities' livelihoods improvement and thereby contributing to the national economic growth and poverty reduction agenda in Tanzania and other countries of the same context.
\end{abstract}

Keywords: Tourism Industry; Tanzania

\section{Introduction}

Tourism is one of the fastest growing industries in developing countries and Tanzania, Zanzibar in particular. The contribution of tourism industry in the global economy is remarkable. According to [1] shows that the tourism industry helps in improving the standard of living, increasing Foreign Exchange Earnings for a country and the Gross Domestic Product (GDP). Other benefits stated include creating jobs and increasing wealth for poor local people and therefore contributing to the alleviation of poverty in a country. This indicates that the tourism industry growth is a high pace in any country growth and development progress and prospects. Due to tourist industry growth and prospects, competition in the use of tourism resources is likely to expand and understanding how local communities participate in and benefit from the industry towards improving their livelihoods is ines- 
capable debate.

Historically, Zanzibar had monoculture economy dependent on cloves before independence in 1964. Following the decline of production and world cloves selling prices, the Zanzibar Government opted for economic diversification involving investment in agriculture, trading, manufacturing, communication and tourism as the lead sectors after independence [2]. The literature shows strongly the tourism industry in Zanzibar began in the late 1980's. It is still a new industry to grow and sustain a living to Zanzibar residents and the Nation at large. The Government of Zanzibar has deliberate effort to strengthen the role of tourism by encouraging local communities to be involved in the sector and therefore reduce poverty in their families. Other initiative is to enact policy and legislature framework to capture the need, control and coordinate them for effective service delivery to residents [2, 3].

Up to the year 1995 after Zanzibar independence in 1964, no tourism policy framework was in place to guide and coordinate the industry. Some initiative by the Government came into being in the year 1996 and beyond. These include enactment of Tourism Promotion Act of 1996, Preparation of the Tourism Master Plan of 2003 and enactment of Tourism Policy of 2004. Both aim to strengthen the industry for effective management of the sector. However, Zanzibar Strategy for Growth and Reduction of Poverty (ZSGRP) was put in place in the early 2000 's as another initiative to reflect the Government commitment for reducing poverty. The strategy among others recognizes Trade and Tourism as leading sectors in the Country development. Tourism industry in the country has proved to be a promising growth sector to the national economy due to its contribution to country development [4].

Despite the fact that tourism is one of the fastest growing industries in the global economy, the industry is continuing facing different challenges. Remarkable challenges include inadequate tourism education, training and awareness, inadequate protection of environment, inadequate funds, inadequate promotion of sector, limited participation of local community, inadequate infrastructures, political interference, energy and crime. These challenges limit the effectiveness of the tourism industry in the world of developing countries. However, community participation in tourism industry can play an important role in increasing national income, personal and household income and therefore increasing standard of living of the poor people in both developing and developed countries of the world.

The tourism sector in Zanzibar is too far behind from reaching this goal due to limited community participation in tourism sector [5]. Apparently, the local communities in Bwejuu Village are not actively participating in the tourism industry, not well informed and finally the abject poverty is at increase, despite the abundant tourism resources in their living area [6]. Inadequate local community participation is a major challenge limiting them gaining extended benefits from the tourism industry in Zanzibar. Likely, the consequence of non participation leads to the conflicts and confrontations between tourist investors, government and local people. This situation disturbs the economic growth and development through foreign exchange earnings, creation of employment opportunities, and provision of public revenues.

\section{Materials and Methods}

Bwejuu is one of the tourist destination Village in Zanzibar. The Village is situated in Eastern Coast in the South District of Unguja, Zanzibar. It is located about 45 Kilometres from Zanzibar Stone Town. The village is located between the Villages of Paje and Jambiani in the south, Michamvi in the north and Ukongoroni in the west. The Indian Ocean borders the Village in the Eastern part. The Villages is easily reachable from Zanzibar city through bus transport numbered 324 (Map 1).

The Villages population has increased from 1842 by the year 2002 to 2050 in the year [7]. The major economic activities performed by inhabitants are fishing, tourism, trade/business, and farming. These activities are main source of employment and income generation and therefore help to sustain livelihood of local communities in Bwejuu Village.

Bwejuu Village was selected due to various reasons with her own potentials existing in the settlement. It is a settlement with community participation in tourism sector. Likely, availability of a wide range of tourism attractions in the Village, diversification of activities and abundant tourist hotels, bungalows and restaurants are other factors giving it its potentials. Similarly, the settlement is along the coastal which surrounded by a very attractive white sandy beach of Indian Ocean, mangrove swamps and coral reefs. In addition, it is a marine recreational area with a diversity of activities including scuba diving, snorkeling, deep sea fishing, sailing boat, lagoons and the offshore inlets, thus it was worth studying for learning.

Simple random sampling was used to explore the case. The type of sampling was selected randomly from the total number of population involved in the Village (Table 1). This type of sampling ensures that any individual element of the population to have an equal and independent opportunity of being selected and also being representative and minimizing sampling biases. Key respondents identified include the Villagers, tour operators, travel agents, tour guide, individuals, central and local government officials (Table 1). Likely, purposive sampling was used to compliment simple random sampling. The Vil- 
1110 Enhancing Tourism Industry through Community Participation: A Strategy for Poverty Reduction in Zanzibar, Tanzania

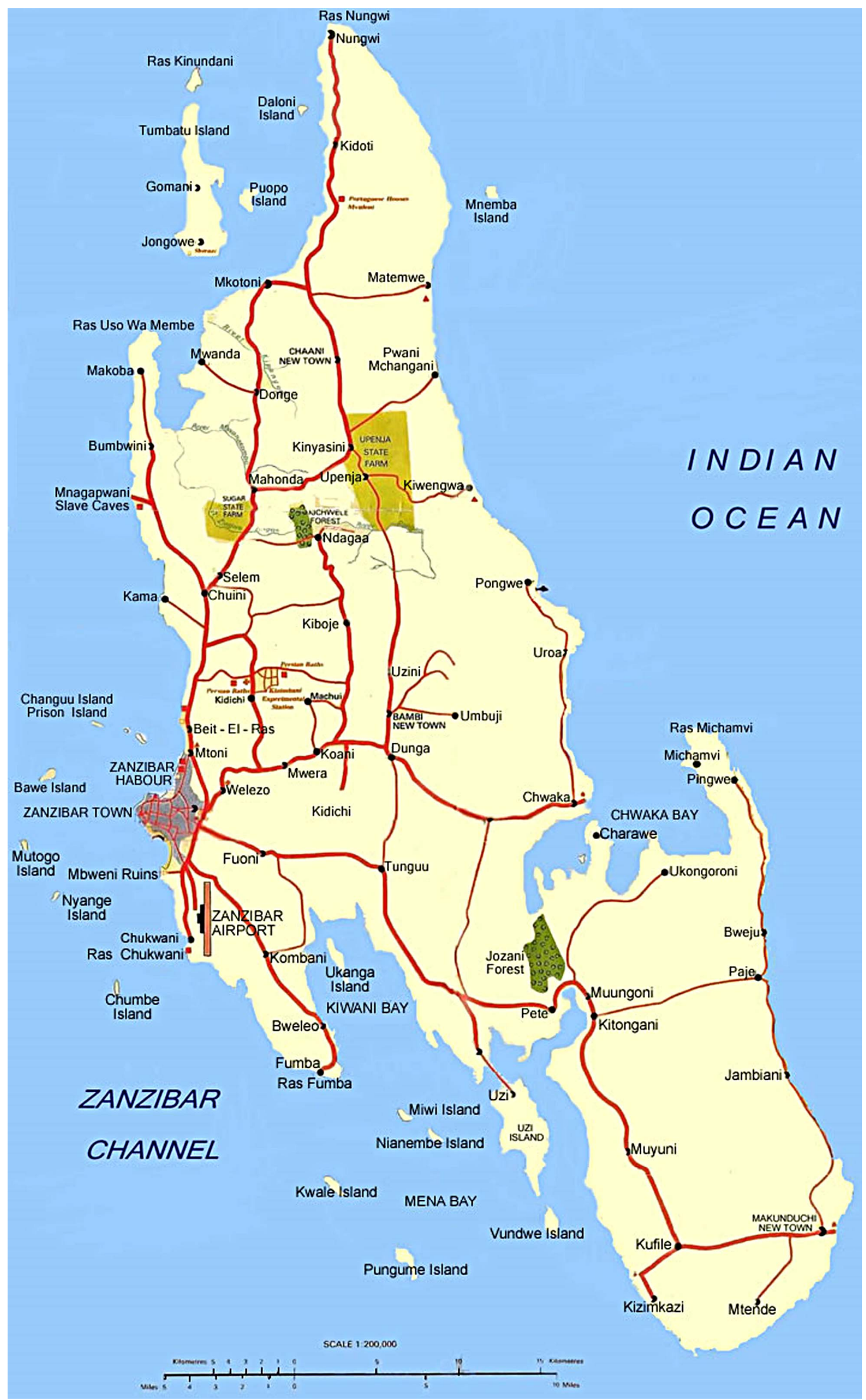

Map 1. Locational map of Bwejuu Village. Source: [8]. 
Table 1. Sample size of the study.

\begin{tabular}{ccccc}
\hline Respondents & Male & Female & Total & \% of distribution \\
\hline Villagers & 109 & 86 & $\mathbf{1 9 5}$ & 68 \\
Tour Operators & 20 & 18 & $\mathbf{3 8}$ & 13 \\
Travel agents & 10 & 10 & $\mathbf{2 0}$ & 7 \\
Tour guide & 8 & 2 & $\mathbf{1 0}$ & 4 \\
Individuals & 8 & 8 & $\mathbf{1 6}$ & 6 \\
Central government staff & 2 & 2 & $\mathbf{4}$ & 1 \\
Local government staff & 2 & 2 & $\mathbf{4}$ & 1 \\
\hline Total & $\mathbf{1 5 9}$ & $\mathbf{1 2 8}$ & $\mathbf{2 8 7}$ & $\mathbf{1 0 0}$ \\
\hline
\end{tabular}

lage and respondents were purposively selected because of their involvement in tourism activities, attractions and investments. The goal of using purposive sampling was to sample study respondents in a strategic way so that those sampled could be relevant to the research questions that were posed. The two sampling type employed in this study help to fulfils the requirements of efficiency, representativeness, reliability and flexibility. A total of 287 respondents were involved in this study from different categories of respondents as presented in Table $\mathbf{1}$.

Interviews, focus group discussions, photographs and participants observations were tools and methods employed in this study. The key question addressed centred on understanding how local communities participates in tourism industry, how do they benefits and any factors influencing their participation in the sector as a poverty reduction and growth development strategy. Both structured and unstructured interviews were done. Interviews were administered by checklist questionnaire deigned and test during the pilot study. These questionnaires were in form of English. Because of the sensitive nature of this issue the local community participation questions were directed to people who participate in various tourism activities. The questionnaires were also distributed into three categories in order to capture the information about general information of study respondents. These include state of tourism industry in Bwejuu Village, community participation in tourism industry, contribution of tourism sector to community livelihood sustainability and factor influencing the local community participation in tourism sector.

Observation involved a systematic selection, watching and recording the behaviors and characteristics of tourism operations, functions and respondents arguments. It helps in probing and learning more about the tourism, community participation and the realities of study phenomena. It includes observation of tourism activities, social services, poverty issues and daily practical livelihood activities performed in the Bwejuu Village. Using this tool, it helps to capture respondents' attitudes and behaviours as well as to validate the real situation through photograph taking. The investigations use eye technique to observe with note taking during observation on various ongoing tourism events in the Village. These were supplemented by photographing and mapping to validate the information collected during the study. Likely, documentary reviews were done. The nature of reviews centres on understanding policy documents, reports and empirical case studies in the area under investigation. Among them include [4,9-11], Books, Papers, Journals and web sites. These documented sources were employed to add value and enriching the primary data.

Furthermore, data collected were analysed. These involve data sorting, organizing and coding before computer software entry. Both qualitative and quantitative nature of data were obtained, organized and analysed. The quantitative data types were in form of nominal and ordinal in nature were presented in form of numbers, percentages, frequencies and tables. They were coded and the number of respondents to specific items conveyed by using descriptive statistics. These have been organized and analyzed using Statistical Package for Social Science Version. With regards to the qualitative questions, responses from the participants were grouped according to topic area and the data were categorized into sub-themes. These data were presented in form of text, narratives and direct quotes.

\section{Results, Discussions and Synthesis}

\subsection{Socio-Economic and Demographic Characteristics of Tourist Operators}

\section{Age structure}

Local communities involving in tourism sector are of different age groups. The study reveals that the age groups between 21 - 30 (28.6\%) years of age are highly involve in the tourism industry. This shows that youths are participating actively in tourism sector rather than the rest of other age group (Table 2).

Education levels of tourism operators

The study revealed that $46.3 \%$ have Secondary Education, 30\% with Primary Education, 10.8\% have Certificate and Diploma, $1.4 \%$ have Degree level and those with no educational background occupy $0.7 \%$, (Table 3). This indicates that the majority of tourist operators who

Table 2. Distribution of actors by sex and age.

\begin{tabular}{ccccc}
\hline Age Group & Frequency & Percent & Male (\%) & Female (\%) \\
\hline $18-20$ & 77 & $26.8 \%$ & $47(61.0 \%)$ & $30(39.0 \%)$ \\
$21-30$ & 82 & $28.6 \%$ & $28(34.1 \%)$ & $54(65.9 \%)$ \\
$31-40$ & 79 & $27.5 \%$ & $58(73.4 \%$ & $21(26.6 \%)$ \\
$41-50$ & 33 & $11.5 \%$ & $22(66.7 \%)$ & $11(33.3 \%)$ \\
$51-60+$ & 16 & $5.6 \%$ & $4(25.0 \%)$ & $12(75.0 \%)$ \\
\hline Total & $\mathbf{2 8 7}$ & $\mathbf{1 0 0 \%}$ & $\mathbf{1 5 9}(\mathbf{5 5 . 4 \% )}$ & $\mathbf{1 2 8}(\mathbf{4 4 . 6 \% )}$ \\
\hline
\end{tabular}


Table 3. Education level of respondents.

\begin{tabular}{cccc}
\hline Education level & Frequency & Percent & Cumulative Percent \\
\hline Primary education level & 86 & 30.0 & 30.0 \\
Secondary education level & 133 & 46.3 & 76.3 \\
Certificate education level & 31 & 10.8 & 87.1 \\
Diploma education level & 31 & 10.8 & 97.9 \\
Degree education level & 4 & 1.4 & 99.3 \\
Other education level & 2 & 0.7 & 100.0 \\
\hline Total & $\mathbf{2 8 7}$ & $\mathbf{1 0 0 . 0}$ & $\mathbf{1 0 0}$ \\
\hline
\end{tabular}

involve in and benefit from tourism industry have secondary education. Education is one factors which observed strengthening tourist industry in Zanzibar particularly, the ability of residents to speak and write English and other foreign languages.

\section{Residence status and tenure}

The study shows that among the 287 total respondents, 231 (80.5\%) are residing in Bwejuu Village with permanent land ownership while the rest 56 (19.5\%) are tenants. This shows how local Village residents are motivated to participate in the tourism sector, as one of the livelihood activity when they found posssing their own Himes.

\section{Economic activities}

Residents living in Bwejuu Village are involving in different livelihood activities (Table 4). Among these activities tourism is the second livelihood economic sector after fishing activity as a leading socio-economic activity, which contributes $25.1 \%$ on direct employment creation to residents. This implies need for its strengthening for the national economy.

\subsection{Tourism Industry Attraction in Bwejuu Village, Zanzibar}

Bwejuu Village is a hub of tourism in Zanzibar. The Settlement has different tourism attraction potentials as presented hereunder:

\section{Tourist hotels}

Hotels are among the tourism attraction area in Bwejuu Village (Plate 1). Village has a total of 27 hotels including bungalows. Among the total hotels, 17 hotels are owned by foreign investors whereas a total of 10 hotels are owned by Bwejuu residents. These hotels differentiate from one star, two stars, three stars, four stars and five stars. The price levels range according to star. The price of hotels belong to first, second and third star vary from 30 up to 150 USD per day while the price of hotels belong to four and five star range from 200 up to 500 USD per day. One criterion for price allocation depends on the star of a hotel and room type. In regard to operation, the study revealed that a total of 23 of hotels are operated by the foreign investors while 4 hotels are operated by Bwejuu residents who are also owner. Others are hired modalities to foreign investors.
Table 4. Respondents' economic occupation.

\begin{tabular}{ccccc}
\hline Economic activity & Frequency & Percent & Male (\%) & Female (\%) \\
Tourism & 72 & $25.1 \%$ & $48(66.7 \%)$ & $24(33.3 \%)$ \\
Fishing & 77 & $26.8 \%$ & $60(77.9 \%)$ & $17(22.1 \%)$ \\
Farming & 70 & $24.4 \%$ & $28(40.0 \%)$ & $42(60.0 \%)$ \\
Trade & 41 & $14.3 \%$ & $19(46.3 \%)$ & $22(53.7 \%)$ \\
Other & 27 & $9.4 \%$ & $14(51.9 \%)$ & $13(48.1 \%)$ \\
\hline Total & $\mathbf{2 8 7}$ & $\mathbf{1 0 0 . 0}$ & $\mathbf{1 5 9}(\mathbf{5 5 . 4 \%})$ & $\mathbf{1 2 8}(\mathbf{4 4 . 6 \% )}$ \\
\hline
\end{tabular}

The above shows that Bwejuu community participates in tourist hotels attraction by providing their resources to foreign investors such as building and land. This is reflected to form of participation for material incentive. This level of participation limits local residents to benefit much from tourism sector. In addition, the study revealed that tourist hotel benefits are there but they are limited to only Bwejuu residents employed in the tourism hotels at unskilled cadres with low wages range from 120,000 to 300,000 per month. The study also revealed that tourist hotel attraction is mainly constraint by inadequate experiences of tourism business, poor tourism education, Islamic rules, culture and seasonality of business.

\section{Beach}

Bwejuu Village is surrounded by a lovely white sandy beach of Indian Ocean in its eastern part (Plate 2). The beach is very attractive to tourists and locals. The beach strides approximately 15 kilometres from southern part to northern part of the Village. It is basically free of charge and a public property. The residents participate by forming volunteer groups to clean, protect and maintain Village beach under supervision of Village Shehia Committee. The beach is a source of tourist arrivals in the Village for sun bathing and recreation. Both volunteer groups and Village Shehia Committee enjoy the tourist arrivals so as to improve their livelihood. In view to malpractices of beach as a challenge, the Village Shehia Committee takes responsibility to discipline anybody who pollutes the beach. On other hand, if the beach is in front of the hotels, the hotel owners must take responsibility to preserve and maintain it for hotel tourism purposes.

\section{Seaweed farming attraction}

This is an economic activity which is used as a tourism attraction in Bwejuu Village. The sea weed is an economic activity done by women (Plate 3). Bwejuu women participate actively in seaweed farming by being consulted whereas men involve actively in seaweed touring. The incomes accrued from this attraction are shared by both women and men for household obligations including family food expenses, children education, housing, clothes and recreational expenses. The tourists enjoy visiting sea weed farmers and paying a total of 20 USD for a trip. The income ranges from 100 to 150 USD monthly 

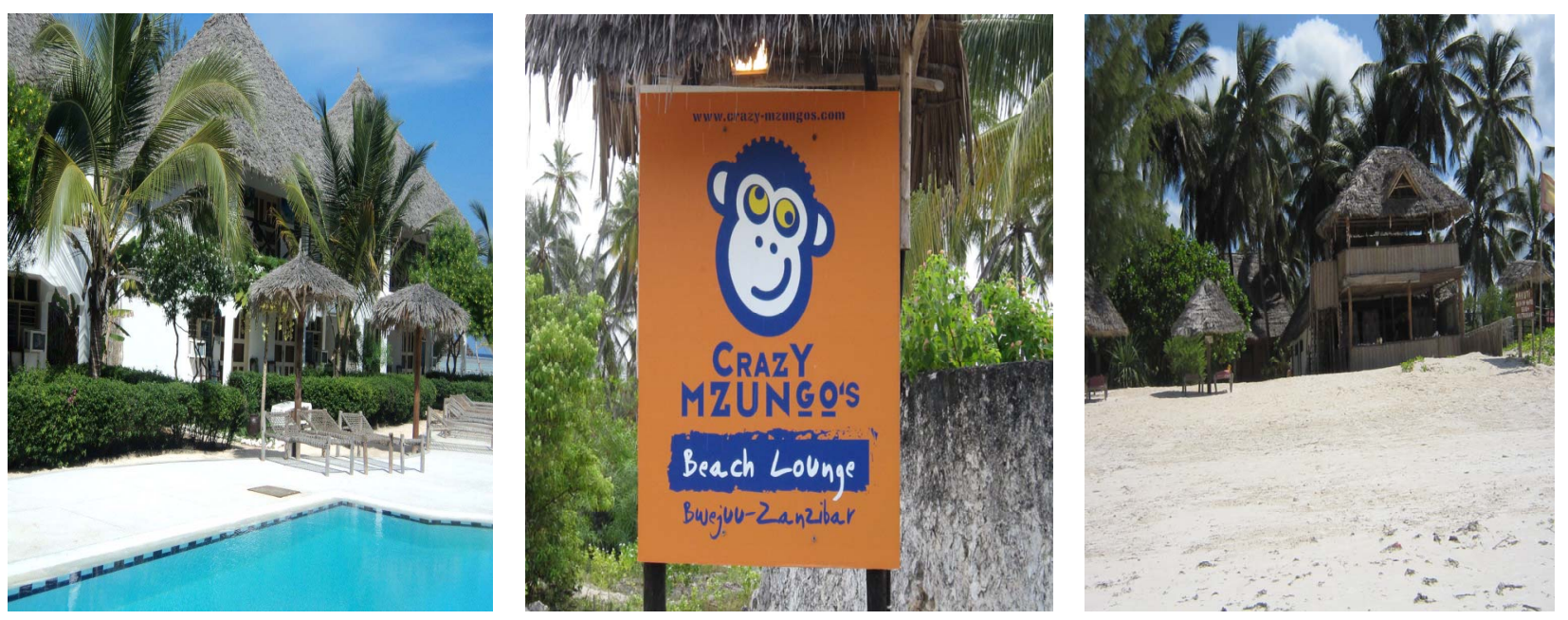

Plate 1. Some tourism hotel and bungalow attractions in Bwejuu Village.
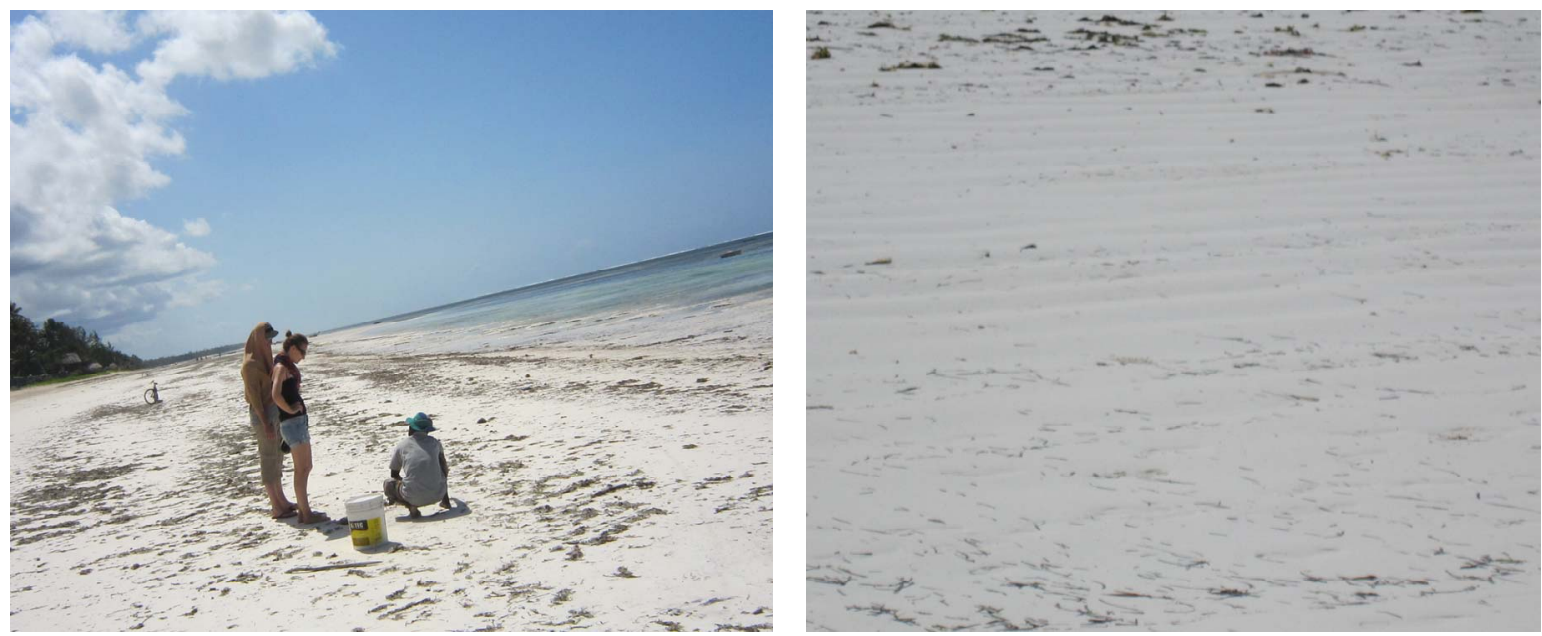

Plate 2. Bwejuu white sandy beach along Indian Ocean in Zanzibar.
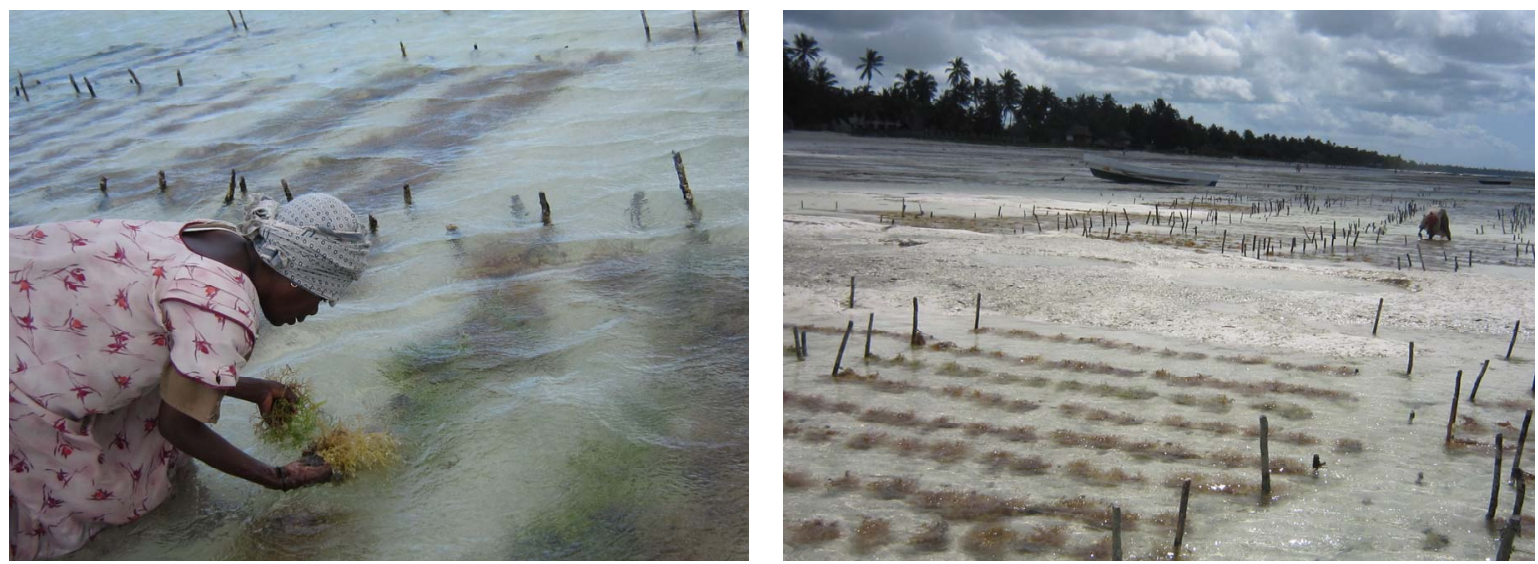

Plate 3. Seaweed farming tour.

at peak season. This activity is carried out only during the sea falling. The study observed that climate change and intensity of extreme weather variability events limits effective operation of seaweed attraction.
Historical building archives in Bwejuu Village

The study revealed that Bwejuu Village was established in $18^{\text {th }}$ century by the immigrants from central part of Unguja Island. During that time, the immigrants saw 
the historical mosque building, cemetery and miza wa miza caves which are now used as a tourism attraction in the Village. It seems that they were built by Shirazi tribe (Arab). The Bwejuu Village is a multi-ethnic, the majority of its people are black African and minority is Arab and Indian/Asian. They are Muslim and speak Kiswahili. The Arab and Indian had shifted from the Village to Zanzibar Town soon after revolution in $1964^{1}$. Bwejuu residents participate in control and management of the attraction and receipt of entry fees. Before doing that tour, tour guides originated from the Village use to report to the Village Shehia Leader for information and payment of entry fee. The tourist is required to pay 5 USD for a head as per June, 2012. Both the Villagers and Village Shehia leadership benefit from this attraction. The tourists are also convinced to donate voluntarily in the Village projects. Amongst projects included education, health, water, environmental conservation and management, most vulnerable children, disabled, and the like. The study revealed that this activity is estimated to attract about 2600 tourists per year and generating about 13,000 USD which is used for community development projects including health and education (Plate 4). In fact, this attraction is strictly restricted by the Islamic norms and rules as well as poor commitment of government to develop and maintain historical building at village level and then to educate the villagers on its importance.

\section{Diving and snorkeling}

The study revealed that Diving and Snorkeling are attractive features for tourists found in the settlement (Plate 5). The Villagers are talking with tour operators, tour guides and travel agents to organize a special excursion for tourists for diving and snorkeling along Indian Ocean in the Village. In organizing this tour per trip, one tourist is required to pay 40 USD as a fee to both organizers namely both villagers and tour companies' expenses. During the tourist season, the Bwejuu community members (seasoned diver) normally earn 400 USD per month by participating in this activity. The benefits accrued are mostly spent for household consumptions and maintenance of equipments. In this study, it was basically found that the Bwejuu Villagers get involved actively in and benefited from this attraction through their self-mobilization participation. The problem associated with this attraction is English language skills for seasoned divers.

\section{Sailing boats attraction}

The study found that sailing boats is a significant tourist attraction existing in Bwejuu Village (Plate 6). The tourists enjoy sailing boats to travel in the Indian Ocean and exercising sea sports. This attraction is organized in collaboration with both villagers and tour companies. Community members (seasoned fishermen) participate in joint analysis (interactive participation) to perform this attraction. The tourists together with locals enter into a sailing boat driven by nature of Indian oceanic winds to go to and from different places $^{2}$. This activity involves also sea sports. The benefits received are jointly shared by both parties who organize the excursion. A total of 40 USD is paid for a head by a trip. This activity generates 360 USD monthly. It sometimes appears a problem of friendly bargaining benefits-sharing between the two parties as there is no formal agreement. Also, sailing boat is faced by the problem of weather variability events for its prosperity.

\section{Coral reefs and lagoons}

The study revealed that coral reefs and lagoons is one area of tourism attraction in Bwejuu Village (Plate 7). The actors involve in this attraction include villagers,
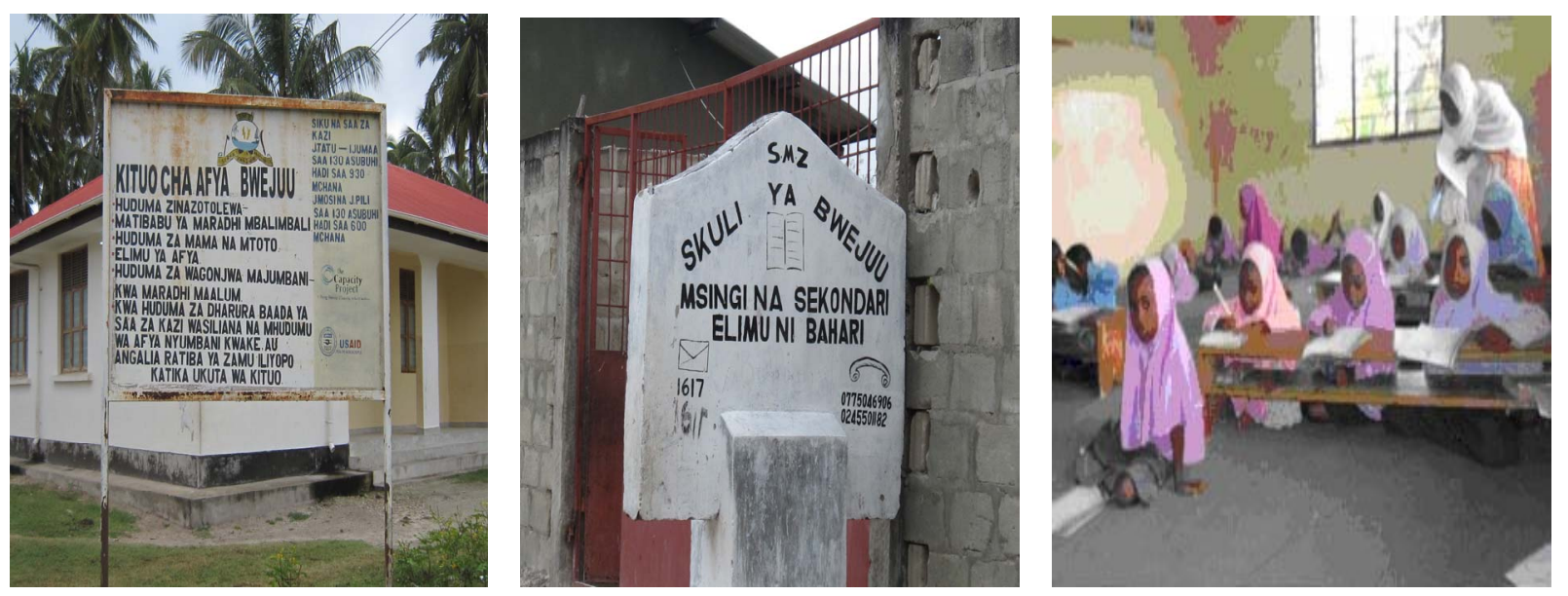

Plate 4. Bwejuu Village health and education projects supported by tourist funds.

\footnotetext{
${ }^{1}$ According to informant, former Bwejuu Shehia leader, Mr. Numba, an old and longtime mosque building constructed by Arabs attracts more than 10 tourists per day during tourist peak season.

${ }^{2}$ Tourists are happy and interesting to learn about travelling to and from with sailing boats.
} 

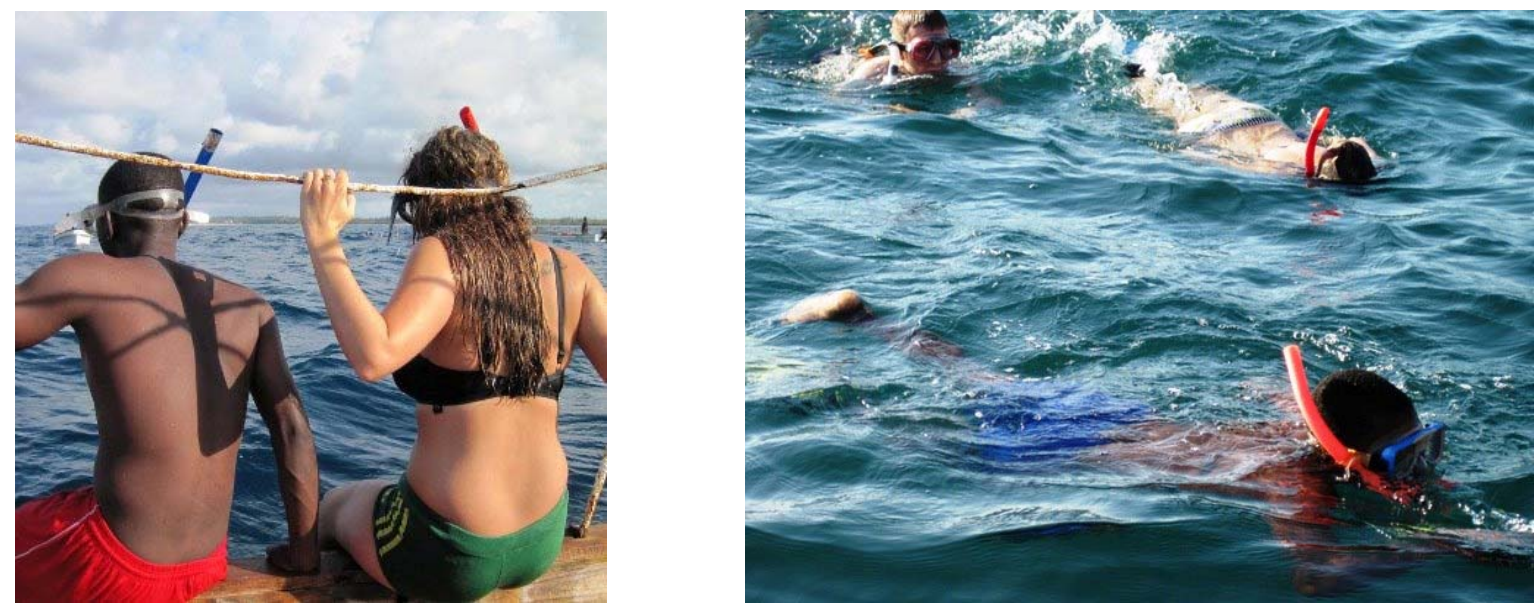

Plate 5. Diving and snorkeling tourism activity.
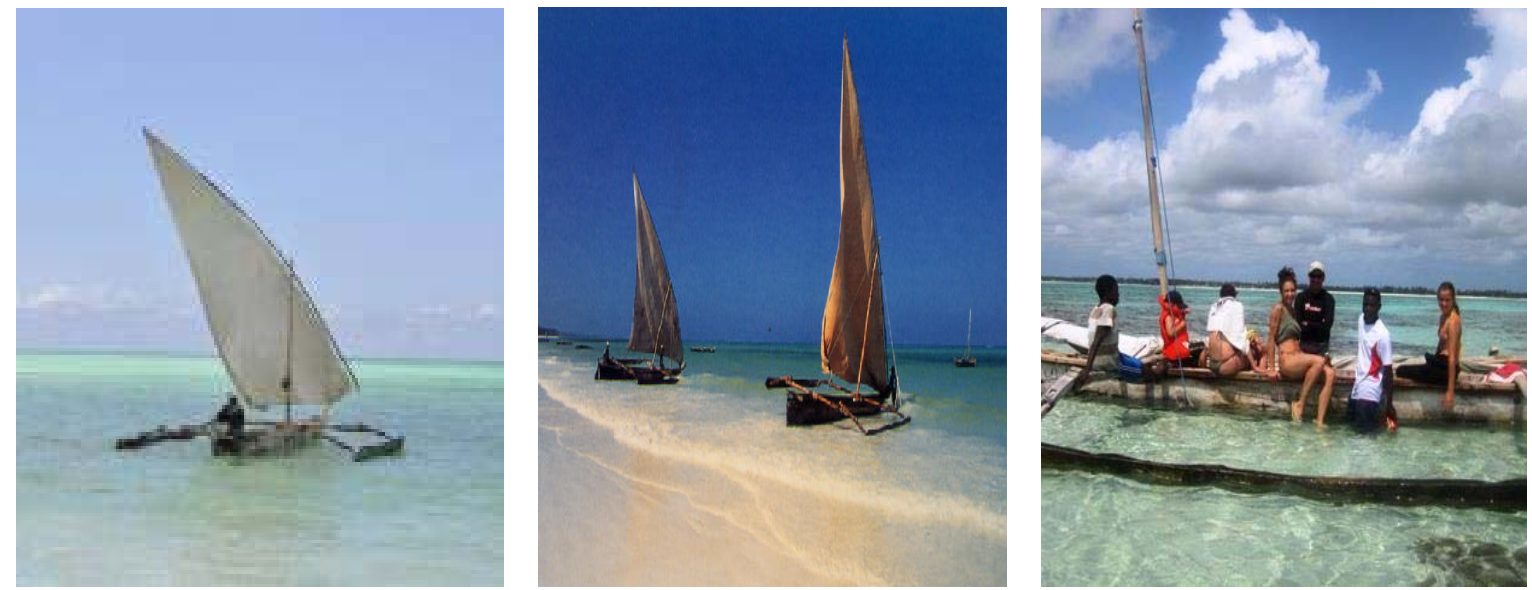

Plate 6. Sailing boats.
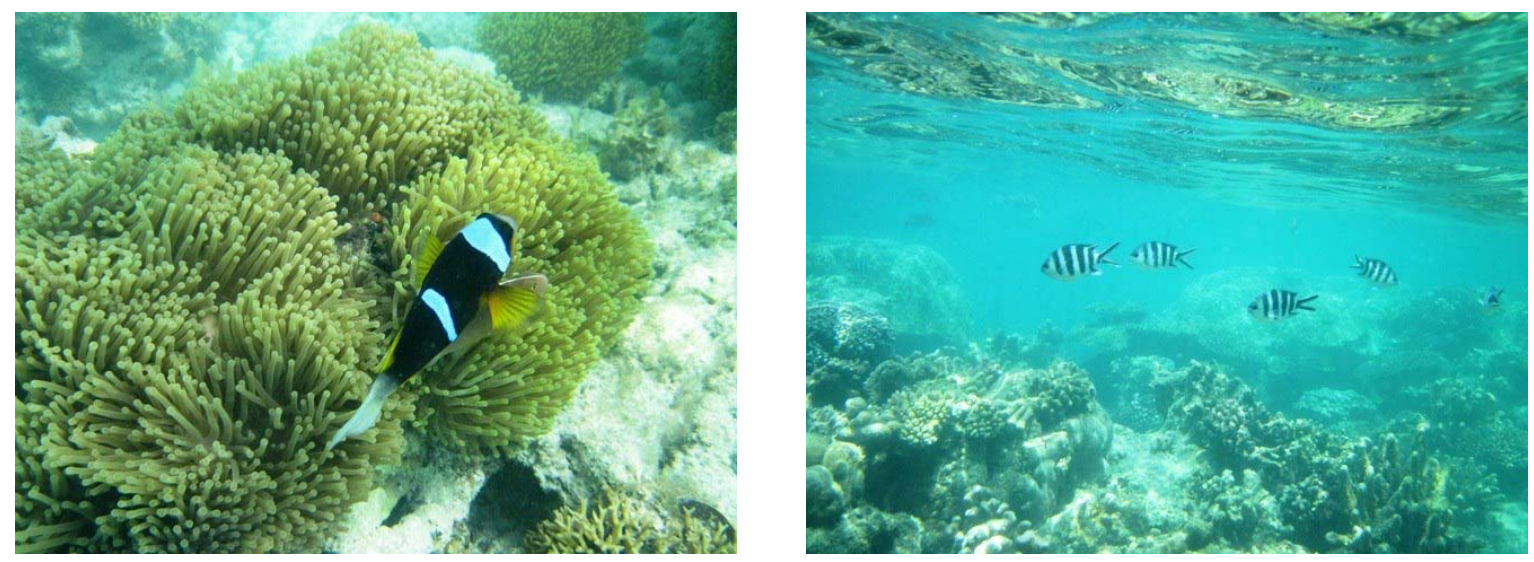

Plate 7. Coral reefs and lagoons attraction.

tour guides and tour operators. The Bwejuu Villagers participate actively in sending the tourists to the coral reefs and lagoons areas to see fish breeding and playing in the Ocean while tour operators participate in arranging that tours on other hand. The tourist is required to pay a total of 30 USD per head and villager gets 15 USD per a trip.
The villager is projected to generate 450 USD per a month. The local Villagers enjoy incomes from their functional participation in this attraction and spend for livelihood sustenance and food security. The study found that illegal fishing practice, poor tourism education and poverty level of local communities are major problems limiting 
effective operation of coral reefs and logoons in Bwejuu Village.

\section{Mangroves and swamps attraction}

The study found that mangrove swamp is another tourism attraction element in Bwejuu (Plate 8). Mangroves are strange trees that have intricate root systems. This is because the mangrove swamps are in brackish water, a mixture of sea salt water and fresh and grow as an extension of a mother tree. This attracts many tourists to visit a Bwejuu Village to see them. The attraction is found at north-western part in the Village and creates jobs for Bwejuu residents. The Villagers participate actively in and benefit from taking the tourists to go to mangrove swamps attraction for 30 USD per a trip. The entrance is 5 USD for adults and 3 USD for children under 15 years. They are paid to the Village Shehia Leadership and they are spent for both Village Development programs and Mangrove swamps conservation and Management Team. Tour guide gets 90 to 300 USD depending on seasonality. One among the major challenges facing this attraction in its prosperity are bad roads, poverty level of the villagers cutting mangroves for firewood and charcoal, climate change, poor tourism education and commitment of government to protect and maintain it.

The general observation showed that Bwejuu Village is endowed with tourism attractions. The findings revealed that there is positive correlation between livelihood improvement and tourism attraction in Bwejuu Village. This implies that local communities are able to change their living standards through participation in tourism related activities. Table 5 shows the contribution of the tourism attractions found in Bwejuu Village and its impact.
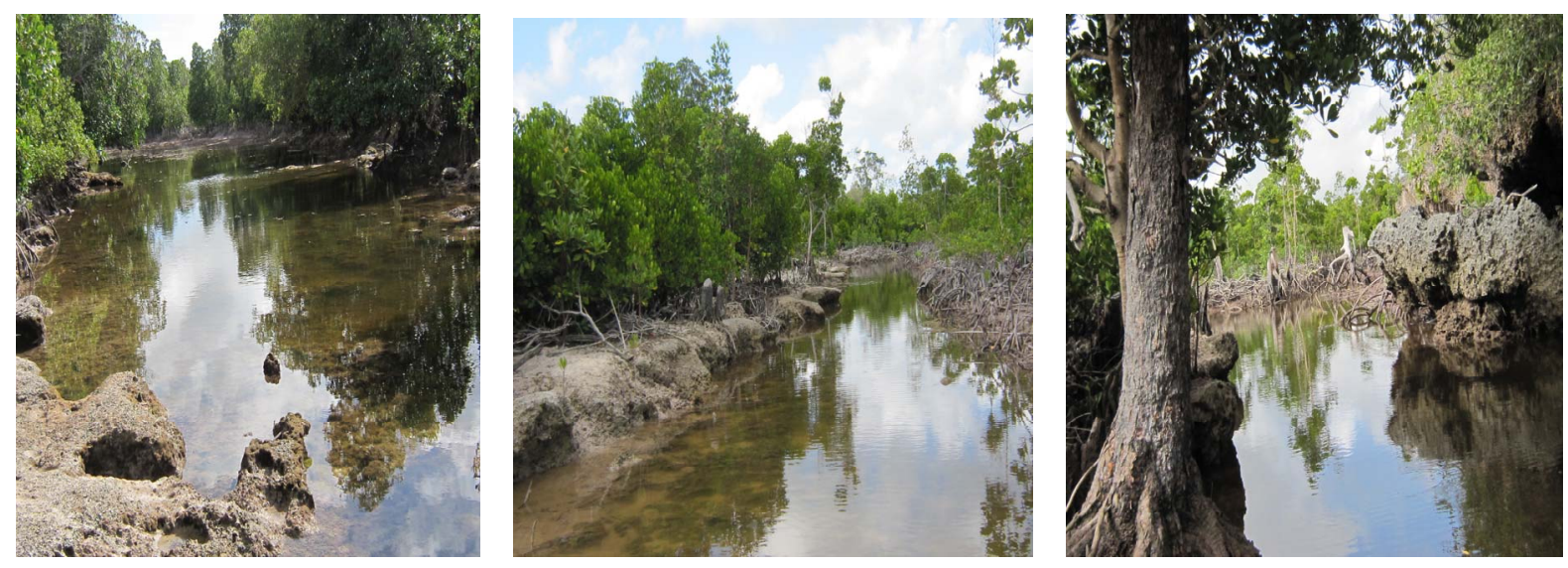

Plate 8. Mangrove swamps attraction in Bwejuu Village.

Table 5. Contribution of the tourism activities in Bwejuu Village.

\begin{tabular}{|c|c|c|c|c|c|c|}
\hline \multirow{2}{*}{ Activities } & \multirow{2}{*}{ Area found } & \multirow{2}{*}{ Operator } & \multirow{2}{*}{$\begin{array}{l}\text { Ownership } \\
\text { status }\end{array}$} & \multirow{2}{*}{ Condition of ownership } & \multicolumn{2}{|c|}{ Contribution/benefit } \\
\hline & & & & & Family & Government \\
\hline Tourist hotels & $\begin{array}{l}\text { Bwejuu } \\
\text { Village }\end{array}$ & $\begin{array}{l}\text { Villagers, travel agents, } \\
\text { foreign investors }\end{array}$ & $\begin{array}{c}\text { Sole \& } \\
\text { Partnership }\end{array}$ & $\begin{array}{c}\text { Adherence with Investment } \\
\text { and Tourism Policies and } \\
\text { Legislations }\end{array}$ & $\begin{array}{c}\text { Jobs creation } \\
\text { Income generations }\end{array}$ & $\begin{array}{l}\text { Foreign exchange } \\
\text { earnings, revenues }\end{array}$ \\
\hline Beach & $\begin{array}{l}\text { Bwejuu } \\
\text { Village }\end{array}$ & Public & $\begin{array}{c}\text { Public } \\
\text { ownership }\end{array}$ & As per constitution of 1984 & $\begin{array}{l}\text { Recreation, } \\
\text { sports }\end{array}$ & revenues \\
\hline Seaweed & Ocean & Villagers, tour guide & individual & As per constitution of 1984 & $\begin{array}{c}\text { Jobs creation, } \\
\text { Income generation }\end{array}$ & $\begin{array}{l}\text { Foreign exchange } \\
\text { earnings }\end{array}$ \\
\hline $\begin{array}{l}\text { Historical Building } \\
\text { Archaives }\end{array}$ & $\begin{array}{l}\text { Bwejuu } \\
\text { Village }\end{array}$ & Villagers, tour guide & Shehia & As per constitution of 1984 & $\begin{array}{c}\text { Jobs creation, } \\
\text { Income generation }\end{array}$ & $\begin{array}{l}\text { Foreign exchange } \\
\text { earnings }\end{array}$ \\
\hline $\begin{array}{c}\text { Diving } \\
\text { and snorkeling }\end{array}$ & Ocean & $\begin{array}{l}\text { Villagers, tour operators } \\
\text { \& Foreign investors }\end{array}$ & Partnership & $\begin{array}{l}\text { As per marine and } \\
\text { tourism Acts }\end{array}$ & $\begin{array}{c}\text { Jobs creation, } \\
\text { Income generation }\end{array}$ & $\begin{array}{l}\text { Foreign exchange } \\
\text { earnings }\end{array}$ \\
\hline $\begin{array}{l}\text { Coral reefs } \\
\text { and lagoons }\end{array}$ & Ocean & $\begin{array}{l}\text { Villagers, tour operators } \\
\text { \& Foreign investors }\end{array}$ & Partnership & $\begin{array}{l}\text { As per marine and } \\
\text { tourism Acts }\end{array}$ & $\begin{array}{c}\text { Jobs creation } \\
\text { Income generation }\end{array}$ & $\begin{array}{l}\text { National income, } \\
\text { earnings }\end{array}$ \\
\hline Mangrove swamps & $\begin{array}{l}\text { Bwejuu } \\
\text { Village }\end{array}$ & Villagers, travel agents & $\begin{array}{c}\text { Public } \\
\text { ownership }\end{array}$ & $\begin{array}{l}\text { Adherence with } \\
\text { Environment and Tourism } \\
\text { Policies and legislations }\end{array}$ & $\begin{array}{l}\text { Jobs creation } \\
\text { Income generation }\end{array}$ & $\begin{array}{c}\text { National income, Foreign } \\
\text { exchange earnings }\end{array}$ \\
\hline
\end{tabular}




\subsection{Actors, Their Roles and Involvement in Tourism Sector in Bwejuu Village}

The study shows different actors involving in tourism activities in Bwejuu Village. Their roles and involvement are presented hereunder.

\section{Government}

The study revealed that Government of Zanzibar is a central actor in promoting tourism sector. It plays a great role of management, coordination and supervision of tourism sector in Zanzibar in view to developing and enactment of Tourism policy, legislations and Plans. It also supports local communities to participate in tourism sector and ensure tourism benefits all people. On the other hand, the Government plays a significant part to ensure a conducive environment for all actors involving in tourism activities. The study found that the Government participated actively in tourist hotels attraction to collect hotel levies and registration but it fails to compile and keep tourist records on tourist arrivals and receipts in the Village. The Government faces with the problems of shortage of staff at Village level to enforce laws related to tourism activities, world economic crisis, and shortage of funds for tourism marketing and promotion and poor infrastructures. These problems limit to attract more tourists and increased government revenues.

\section{Tour operators/companies}

The study revealed that tour operators/companies participated in tourism attraction sites practiced in Bwejuu Village. These included tourist hotels, diving and snorkeling, sailing boats as well as coral reefs and lagoons attractions. At this category of actors, it was observed that both functional participation and self-initiated mobilization were predominant. It has revealed that the main roles played by tour operators in tourism activities included transportation, booking for accommodation and catering, excursion, entertainment arrangement, as well as marketing and promotion of tourism activities. In performing their duties, tour operators are facing the following constraints that are cancellation of booking by tourists, global economic crisis and security concerns.

\section{Travel agents}

Travel agents are crucial actor for developing tourism sector. The study found that the travel agents involved actively in tourist hotel and mangrove swamps attractions in Bwejuu Village. They participate in through both by consultation and for material incentive to execute their tourism activities. The roles played by travel agents in daily basis are transportation, booking and reservations, air ticketing as well as tourism marketing and promotion. In doing their roles, the study observed that travel agents encountering the challenges of competition and postponement of bookings.

\section{Tour guide}

Tour guide was another important area of tourism sec- tor found in this study. The study revealed that tour guides participated in the hotels, historical development of the Village settlement, seaweed farming and mangrove swamps. Their participation was reflected in form of both information giving and consultation. It was also found that a major role played by tour guides was to direct tourists in different places of tourists' interest. In this study, it was observed that tour guides were constraint by the climatic changes and security concerns

\section{Villagers and individuals}

The study revealed that Villagers and Individuals were also central actor in tourism sector in their locality. The study found that the villagers were involved in and benefited from all eight tourist attractions found in the Village. These tourist attractions included hotels, beach, seaweed farming, historical building archives, diving and snorkeling, sailing boats, coral reefs and lagoons as well as mangrove swamps. Their participation cut across all levels from passive to self mobilization (active). They play a great role in control, implementation, monitoring and evaluation. The study found that the villagers were faced with the challenges of education, infrastructures, culture, and poverty level.

\subsection{Levels of Community Participation in Tourism Industry}

The study revealed that $44 \%$ of the total respondents agreed that they have been involved actively in the implementation and uses of the tourism attractions and enjoy the benefits. It was also found that $4 \%$ of total respondents participated passively. Also, the study found that about $11 \%$ of total respondents participated in information giving to tourists in relation to historical building archives, mangrove swamps, seaweed, coral reefs and lagoons. Moreover, the study observed that $9 \%$ of the total respondents participated by giving consultation to tourism attractions and 9\% of the total respondents participated by functional such as forming associations to coordinate and operate tourism ventures. In addition, 17\% of total respondents participated for material incentives such as renting of land and buildings for tourist hotels whereby $6 \%$ of total respondents argued that they had participated by interactive through joint ownership and operations of tourist hotels and tour companies (Table 6).

Generally, study revealed that local communities in Bwejuu Village participate in different tourist activities. This has contributed to employment opportunities to majority of residents. On the other based on practical reflections, the study revealed that about $77 \%$ of the total respondents argued that they had involved actively in the areas of implementation and operationalization of the tourism attractions found in the case study area. It was also found that $7 \%$ of the total respondents had partici- 
pated in monitoring and evaluation of tourist attractions, $6 \%$ of the total respondents participated in tourism planning and $5 \%$ of the total respondents participated in decision-making as well as coordination and control towards tourism attraction in Bwejuu Village (Table 7).

In general, the area of implementation and operationalization of tourism attractions has a great implication in improvement of the livelihood of the villagers since it provides the best room for the actors and villagers in particular, to get jobs and hence generate incomes for their participation.

\subsection{Contribution of Tourism Industry in Sustaining Community Livelihoods}

The study revealed that tourism industry is of great importance to sustain community livelihoods in the settlement. The following contributions were earmarked.

\section{Employment creation}

The study revealed that tourism attractions in Bwejuu Village have been a source of employment for local communities, both women and men of different age groups in Bwejuu Village. The study results indicate that there is

Table 6. Levels of community participation in tourism sector in Bwejuu.

\begin{tabular}{ccc}
\hline Levels of participation & $\begin{array}{c}\text { Frequency of } \\
\text { Respondents }\end{array}$ & Percent \\
\hline Passive participation & 12 & 4 \\
Participation in information giving & 32 & 11 \\
Participation by consultation & 25 & 9 \\
Participation for material incentive & 50 & 17 \\
Functional participation & 25 & 9 \\
Interactive participation & 17 & 6 \\
Self-mobilization/active participation & 126 & 44 \\
\hline TOTAL & $\mathbf{2 8 7}$ & $\mathbf{1 0 0}$ \\
\hline
\end{tabular}

positive relationship between tourism activities and benefits such as employment, incomes, revenues, leisure, schooling, health, house construction and household consumption (Table 8). The study revealed that $98 \%$ of total respondents were employed in the tourist hotels found in Village including 196 males and 86 females. This is an indication that tourist hotels attraction is cornerstone for jobs creation and earnings. This, therefore, has an implication that earnings from employment sustain livelihood of the poor because people are able to meet basic needs and relative needs. One villager said that $^{3}$ :

\section{Leisure}

The study revealed that $86 \%$ of total respondents involved in the study agreed that they have got relaxed from their participation in beach tourism attraction found in the Village (Table 8). It was observed that some respondents spare time to send their family along the beach for relaxation and recreational activities. This implies that there is good relationship between community participation and improved livelihood since recreational activities increased day to day in the Village.

Table 7. Distribution of areas of participation in tourism attractions.

\begin{tabular}{ccc}
\hline Areas of Participation & $\begin{array}{c}\text { Frequency of } \\
\text { Respondents }\end{array}$ & Percent \\
\hline Planning & 18 & 6 \\
Decision-making & 13 & 5 \\
Implementation/operationalization & 221 & 77 \\
Coordination and control & 14 & 5 \\
Monitoring and evaluation & 21 & 7 \\
\hline Total & $\mathbf{2 8 7}$ & $\mathbf{1 0 0}$ \\
\hline
\end{tabular}

Table 8. Contribution of tourism to community livelihoods in Bwejuu Village.

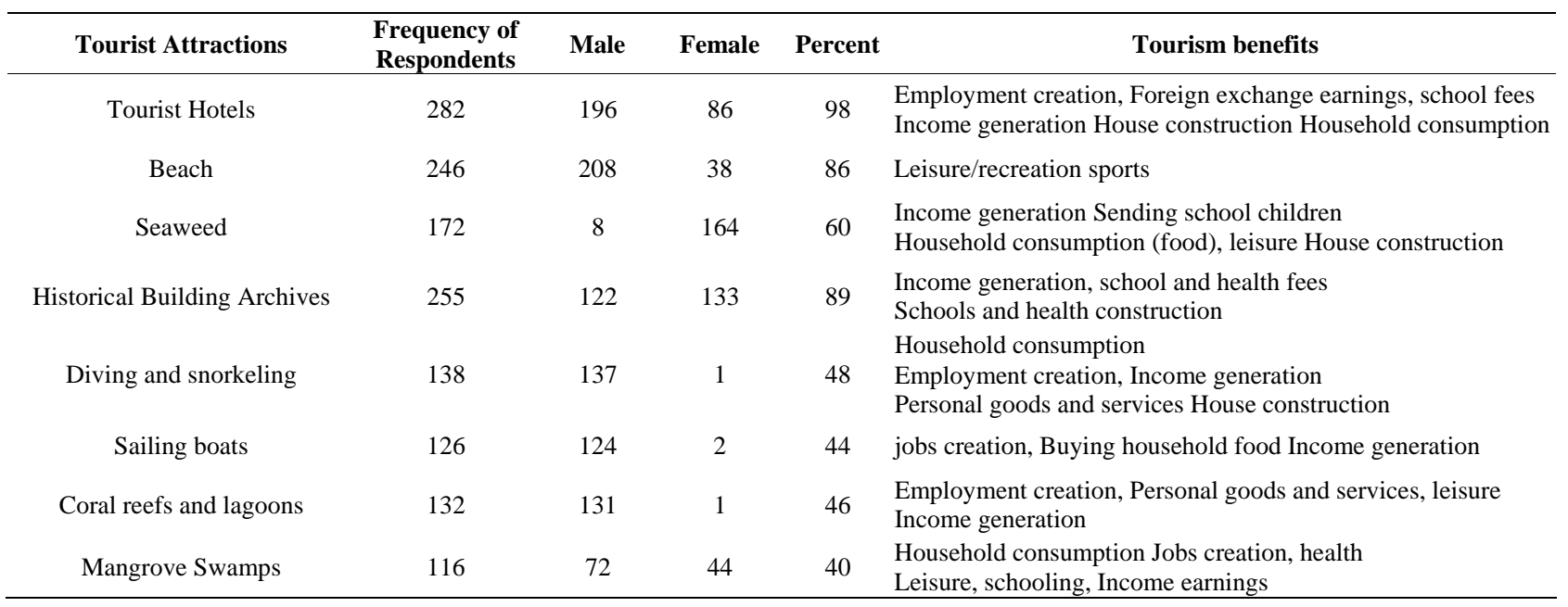

${ }^{3}$ I feel very joyful with my income generated from tourism activities since I am able to send my children to school and afford my daily household consumption comfortably. 
Generally, the study observes that tourist hotels attraction has a great impact to attract more Bwejuu residents rather than the rest since it provides wide room for their economic livelihood opportunities and active participation in tourism sector.

\section{Income generation and expenditure pattern}

The study revealed that it was not very easy work to get accurate income level of respondents involved in this study. The study, therefore, presents only the frequency of respondents by income range who received monthly from their participation in tourism and other activities (Table 9). This reflects on impacts of tourism and other activities such as fishing, farming and trading. The study indicates that the income range from tourism activities is at good trend of increase rather than income range from other related activities. This has a great influence on livelihood sustainability of the poor people since their expenditure pattern tends to change due to increased incomes accrued from participation in tourism activities.

The study also revealed that $97 \%$ of the total respondents interviewed in this study argue that expenditure pattern has gone simultaneously to income earned in the study area. They also stated that their purchasing power is at increase for both basic needs such as food, clothes, housing and they have owned household assets such as houses with items fridges, radio, TV, beds, cupboards, bicycles, and mobile phones for their participation in tourism activities. This is reflected on the question of assets ownership from participation in tourism activities.

The study found that fishing in Bwejuu Village is a primary source for income generation towards improvement of livelihoods of the inhabitants and poverty reduction at family level (Table 9). This is obvious that the Village is along the Indian Ocean. The study also indicates that tourist activities generate more income rather than farming, fishing and trading. This implies that tourism sector has a great impact on sustainable livelihood strategies and hence it is more attractive sector.

\section{Increasing government foreign exchange earnings}

The study revealed that tourism industry is one of the key foreign exchange earnings in Zanzibar Government. $87.5 \%$ of government staff respondents interviewed argued that tourism contributes significantly to the National GDP about 22\%, government revenues about $80 \%$, employment creation about 36,500 direct employments and 201,000 indirect employments, balance of payment, diversifying the economy, and promoting infrastructure projects which also serve other sectors of economy such as fishing, farming and services sector [11].

\subsection{Factors Hindering Community Participation in Tourism Activities in Village}

Tourism activity in Bwejuu Village revealed to play a great role in terms of improving livelihood of the local communities in Zanzibar as explained in Tables 5 and $\mathbf{8}$, however there are some remarkable constraints that affect its effectiveness in the Village as explained here under;

\section{Language barriers}

The study revealed that $21.6 \%$ of the total respondents involved in this study agreed that English is a great constraint hindering Bwejuu Community to participate actively in tourism activities (Table 10). This is an indication that the problem of language leads to passive participation and has been reducing income level to sustain livelihood of the Bwejuu communities. It seems that language classes in particular English is crucial for selfinitiated mobilization.

\section{Inadequate experience in tourism business}

The study result indicates that $12.1 \%$ of total respondents in the study argued that they have participated in tourism business by consultation because they do not have enough experience to run their business competently (Table 10). This is evidence that $15 \%$ of the total tourist hotels found in Bwejuu Village are managed by the Villagers. This reflects on exclusive aspect and decrease livelihood opportunity. Thus, tourism policy and legislation needs to be reviewed to integrate tourism management experience concern and local community needs.

Inadequate training of various actors on tourism and its operation

The finding reveals that tourism education and aware-

Table 9. Income generation activities.

\begin{tabular}{ccc}
\hline Activity & $\begin{array}{c}\text { Frequency of } \\
\text { Respondents }\end{array}$ & $\begin{array}{c}\text { Income Range } \\
\text { per Month (Tsh) }\end{array}$ \\
\hline Tour guiding & 10 & $300,000-600,000$ \\
Tour operating & 38 & $500,000-2,500,000$ \\
Travel agency & 20 & $300,000-600,000$ \\
Farming & 72 & $50,000-200,000$ \\
Fishing & 77 & $100,000-300,000$ \\
Trading & 41 & $100,000-400,000$ \\
Tourist hotel & 29 & $120,000-300,000$ \\
\hline Total & $\mathbf{2 8 7}$ & \\
\hline
\end{tabular}

Table 10. Factors hindering community participation in tourism industry.

\begin{tabular}{ccc}
\hline Problem Identified & $\begin{array}{c}\text { Frequency of } \\
\text { Respondents }\end{array}$ & Percentage \\
\hline Language barriers & 62 & 21.6 \\
Inadequate experience in tourism business & 35 & 12.1 \\
Poor tourism education & 55 & 19.2 \\
Islamic rules and culture & 46 & 16 \\
Poor commitment of tourism actors & 30 & 10.5 \\
Poverty level & 59 & 20.6 \\
\hline Total & $\mathbf{2 8 7}$ & $\mathbf{1 0 0 . 0}$ \\
\hline
\end{tabular}


ness is an important instrument for human development and livelihood. $19.2 \%$ of total of respondents agreed that they have not been involved actively in the tourism industry simply because they were not deeply educated and aware of tourism (Table 10). This is a major concern hindering community participation in tourism sector in Bwejuu Village. Bwejuu residents are not trained on the advantages and disadvantages of tourism sector despite of plentiful tourist resources surrounded in the Village. This is evidence from the study that Bwejuu residents have employed in the tourist hotels and working in the low cadre skilled positions of employment include housekeeping, cleaning, gardening, driver and security. Thus, capacity building is highly needed to address this constraint.

\section{Islamic rules and culture}

It is evident that tourism as an agent of transformation. It can change not only physical and economic conditions but also social and cultural relationships of a community where it has been adopted. Tourists from different parts of the world have different cultures and these tend to influence and change the socio-cultural set up of the host community. The demonstration effect on host communities is often made in clothing, consumption patterns, language and general way of life that tend to imitate the tourists. Zanzibar is of no exception from this. The results of this study indicate that $16 \%$ of total respondents agreed that culture and Islamic rules impede participation in tourism activities in the Village (Table 10). It was found that cases were presented and discussed before Village Shehia committee and family level to control and minimize antisocial behavior such as way of dressing, robbery, alcohol and prostitution. These things are against their Islamic rules and remain unacceptable in the Village. It was also observed that the Villagers are very much concentrated on their traditional way of life because they fear of tourism threatening local cultures and lifestyle.

\section{Poor commitment of actors}

The study revealed that tourism industry has been a source for accessibility to social services and hence improve livelihoods in Bwejuu Village. 10.5\% of total respondents in the study argued that poor commitment of actors was an impediment to local community participation in tourism activities and livelihood improvement (Table 10). This study revealed that infrastructures such as roads, airports, electricity, water, school, hotels and communication network are prime importance for active participation and lifted livelihood strategies. Therefore, deliberate commitment of tourism actors, government in particular is needed to improve tourism sector, self-initiated participation and livelihoods.

\section{Poverty level}

The study revealed that $59 \%$ of the total respondents argued that they face challenge to have enough resources especially fund for tourism investment projects although they are willing to actively participate in tourism industry for sustained livelihoods (Table 10). This reflects on participation for material incentives as they require resources.

In general, the study observed that in spite of the potentiality for improving livelihood of the local communities and hence reducing poverty level through participation in tourism sector, not all Bwejuu residents participate actively in tourism attraction activities. This situation is caused by the different factors affecting them as identified in Table 10. In real practice, these factors have been reducing community participation in tourism activities and improved livelihoods. Specifically, language barriers with $21.6 \%$, poverty level with $20.6 \%$ and poor tourism education with $19.2 \%$ as the leading factors.

\section{Conclusion and Recommendations}

This study has shown that the ladder of participation theoretical view underpinning empirical work can have significant effect on the local communities to participate in tourism activities for improving livelihoods. This underlines the point that theoretical choice can realize significant and reliable explanation relevant to both the local people's participation in tourism industry and livelihoods sustainability of the local people. This supports Maslow's Hierarchy of Human Needs [12] that people must first meet the basic needs of survival before they can move towards fulfilling higher needs. It was found that the impoverished local communities could not move up this hierarchy owing as well to higher level of participation, amongst other reasons, to the inability of the existing tourism activities and structures to uplift them.

Study indicates that tourism industry can be used as a goal to sustain and improve livelihoods of the poor community and hence reduce poverty at personal, household and national levels. In this study, it is quite evident from the research findings that the inadequate local communities' participation in tourism activities results from both the lack of relevant knowledge amongst the local communities and poor management of tourism activities. Others include language barriers, inadequate experience in tourism business, culture, poor commitment and poverty increase. Hence discovering ways of achieving sustainable local community participation in tourism activities is a challenging task, as there is only inadequate coordination strategy in the study area at present. All in all it has been revealed that local community participation is instrumentally a tool to empower local people so that they can actively influence the process of planning, decision-making that affect their improved livelihoods.

It was revealed that tourism policy has been in place since in 2004 but there was no effective enforcement towards its operations and development. The study has 
investigated that there is a need to ensure policy review and amendment is in place to capture local community needs and create more conducive enabling environment including policy enforcement mechanism and community participation in tourism attractions for improving their livelihoods.

After critically reviewing these results reflections, the following conclusions were drawn and recommendations made:

The study revealed that both areas stipulated as function requirement are hardly performed in practice as well as poor community awareness on the Act experienced among the respondents interviewed. This shows the need to review in order to create more conducive enabling environment that encourages and empowers community participation in tourism sector at grassroots level and be able to execute the stipulated functions. The main weakness and challenge comes from the area of enforcement of the Act as a serious drawback of engagement opportunity to local people and deficit of tourism government budget to effectively execute responsibilities. These issues are crucial for tourism development and must be integrated into the Act.

In regard to Tourism Policy, The Revolutionary Government of Zanzibar has adopted [9]. This is among the government's strategies and efforts of developing and strengthening the tourism sector in Zanzibar. The objectives of Tourism Policy are;

1) To utilize more effectively the tourism potential to generate more income, human resources, foreign exchange earnings while protecting the environment, Zanzibar culture and traditions.

2) To diversify the tourist attractions in order to achieve a balanced growth of the tourism industry and maximum benefit, and to strengthen the cultural industries including museums, theatres, cultural and community participation as a product diversification to harness tourism.

3) To formulate and develop marketing plans and promotion programs that maximizes the financial revenues, and the economic, social, cultural and environmental positive impacts.

4) To emphasize the fruitful public/private partnership in tourism sector.

5) To contribute to the quality of local people lives.

6) To stimulate the participation of local people of the tourism development process.

It was noted that among the total 287 respondents interviewed 92\% were not involved in the formulation and developing the policy. Important issues like Tourism Education, Training and Professionalism are not clearly addressed by the policy and which solely seems to be a setback in empowering local community to have more benefits of their participation in the tourism sector. These facts lead local communities living in tourist attraction areas not sufficiently benefiting from the sector due to policy and legislature constraints.

\subsection{Concluding Remarks}

The main problem statement established that inadequate local community participation is a major challenge limiting them gaining extended benefits from the tourism related activities within Bwejuu Village in Zanzibar. The study in summary pinpoints the following:

1) The main tourist activities found in Bwejuu Village are tourist hotels, beach, seaweed, historical building archives, diving and snorkeling, sailing boats, coral reefs and lagoons as well as mangrove swamps. In these activities, $98 \%$ of the Bwejuu residents were participated in and benefited from these tourist attractions. This study, therefore, concludes that increased local involvement and participation will help to ensure people's empowerment in improvement of local communities' livelihoods.

2) The contribution of tourism sector in sustaining community livelihoods is very remarkable. Eight Tourism attractions found in Bwejuu Village have been a crucial source of sustainable livelihoods for local communities, both women and men of different age groups through employment, leisure, income generation, increased government revenues, schooling, health, house construction and household consumption. This is an indication that $97 \%$ of the total respondents interviewed agreed that there is positive correlation between livelihood improvement and tourism activities. The study, therefore, concludes that the tourism sector is essential sector for sustainable livelihoods and thereby contributing to the national development agenda of poverty reduction.

3) Main factors hindering effective community participation in tourism activities performed in Bwejuu Village are language barrier, inadequate experience in tourism business, poor tourism education and training, Islamic rules and culture, poor commitment of actors and poverty level. In real practice, these factors have been reducing Bwejuu residents to participate actively in tourism activities and improved livelihoods. Thus, the study concludes that capacity building programmes are highly needed to overcome these challenges so that local communities participate actively in and benefit more from tourism activities.

In conclusion, it can be asserted that if tourism developers believe that local communities will be satisfied if they are used as labourers instead of being ownership of tourism activities. These communities must be actively involved in each stage of tourism planning and development in order to ensure that all their tourism activities and products benefit the residents. This will represent a significant step forwards in ensuring more adequate community participates in the industry. Policy environment 
must also be created conducive to encourage local communities to own and engage in tourism activities.

\subsection{Recommendations}

This study is needed to enhance community involvement in tourism sector. However, there are some remarkable constraints and challenges towards enhancing community participation in tourism sector for improved community livelihoods. In this respect, the study recommends the following strategies:

1) Government may opt to ensure that local communities' involvement and participation in the tourism sector in their living area through tourism education, training and awareness creation programmes. This will help to build trust in planning process, decision-making process, coordination and control, implementation, monitoring and evaluation of tourism activities.

2) Tourism policy and legislations need to be reviewed and amended in order to create more conducive enabling environment that encourages and empowers community participation in tourism sector at grassroots level and be able to execute the stipulated functions. This will assist local people to enhance their participation, getting more jobs and improve livelihoods opportunities for their wellbeing and therefore contribute to national efforts in poverty alleviation. These issues are very crucial for tourism development and must be integrated into the favorable development policy and Act.

3) In order to attract more tourists in Bwejuu Village and Zanzibar at large to be a single tourist destination in Africa and world as whole, there should be an imperative need for the government to invest on the construction of infrastructures and facilities shared by both residents and tourists as important features for tourism attractions. This will help to increase government revenues, foreign exchange earnings and poverty reduction at family and national levels.

4) The study suggests that for success of tourism industry in Bwejuu Village and Zanzibar, local communities as central stakeholder should be directly and formally recognized through the policy and hence they should be able to play its significant part.

5) Regarding both language barrier and poor tourism education have been identified as central challenges limiting local people to actively participate in tourism Industry and accessing to tourism employment opportunities and earnings, there should be an urgent need to institute training programmes at the local community level that will ultimately provide opportunities for the local people to be employed in skilled positions/cadres with high remuneration and work professionally.

6) Tourism Village Shehia Committee is of prime importance to be legally established in Bwejuu Village. This will enhance urgent need of community participation in tourism sector for improving their livelihood and poverty reduction efforts.

\section{Acknowledgements}

We would like to thank Bwejuu Village communities for their support in providing valuable information for this research. In-depth thanks go to the Government of Revolutionary of Zanzibar for financing this study. We thank you all.

\section{REFERENCES}

[1] WTO, "Developing Sustainable Tourism,” World Tourism Organization, Madrid, 2000.

[2] M. Abdalla and S. Othman, "The Role of Tourism in National Development," Paper Presented at Tourism Seminar on 30 April 1996, North Region, Unguja, 1996.

[3] M. Makame and E. Boon, "Sustainable Tourism and Benefit-Sharing in Zanzibar: The Case of Kiwengwa-Pongwe Forest Reserve,” Journal of Human Ecology, Vol. 24, No. 2, 2008, pp. 93-109.

[4] United Republic of Tanzania (URT), “Zanzibar Strategy for Growth and Poverty Reduction (ZSGPR),” Ministry of Finance and Economic Affairs, Government Printer, 2007.

[5] Zanzibar Economic Bulletin, "A Quarterly Review of the Economy, Vol. 2 No. 4,” Revolutionary Government of Zanzibar, 2009.

[6] Y. Ngaga, et al., "Support for Community Based Conservation and Sustainable Use of Natural Resources in Menai Bay, Zanzibar: Mid-Term Evaluation Final Report. Menai Bay Conservation Area (MBCA),” WWF-Tanzania Programme Office, Ravili, Spalding, 1999.

[7] United Republic of Tanzania (URT), "Population and Human Settlement Census Report,” Government Printer 2012.

[8] Zanzibar Location Map, 2012. www.zanzibartourism.com

[9] United Republic of Tanzania (URT), “Zanzibar Tourism Policy," Ministry of Tourism and Trade, Government Printer, 2004.

[10] United Republic of Tanzania (URT), “Zanzibar Tourism Promotion Act,” Government Printer, 1996.

[11] “Zanzibar Tourism Statistical Report,” Government Printer, 2011.

[12] M. Akunaay, et al., "Community Based Tourism in Tanzania, Potentials and Perils in Practice,” 2nd Peace through Tourism Conference, Dar es Salaam, 7-12 December 2003. 